\title{
Self-Reported Selected Zoonotic Diseases among Animal Handlers in Ahmedabad City
}

\author{
Krupali B. Patel ${ }^{\star 1}$ and Dr. Deepak B. Saxena ${ }^{2}$ \\ ${ }^{1}$ Center for Development Research (ZEF C), Bonn University, Bonn- 53113, Germany; ${ }^{2}$ Indian Institute of Public Health Gandhinagar, \\ Gandhinagar, India
}

\section{Objective}

The present study aims to document the burden of self-reported selected zoonotic diseases $(\mathrm{Z} / \mathrm{D} / \mathrm{S})$ among animal handlers in urban areas of Ahmedabad

\section{Introduction}

The usual mechanism of disease or infection transmission from vertebrate animals to humans and vice-versa is classified as zoonosis [1]. Globally out of all microbial pathogenic disease, $61 \%$ are zoonotic with $13 \%$ species are regarded as emerging or reemerging [2]. Studies suggest the prevalence of innumerable known and important $\mathrm{Z} / \mathrm{D} / \mathrm{S}$ such as leptospirosis, rabies, avian influenza but the extent of burden of zoonotic diseases amongst high-risk cohorts such as animal handlers within urban geography not adequately documented

\section{Methods}

A cross-sectional study conducted amongst animal handlers residing in the urban/peri-urban areas of Ahmedabad. A purposive sample of 170 animal handlers was included in this study. The sample size estimated based on operational feasibility and response saturation for $10 \%$. All individuals engaged in handling animals (such as cattle, buffalos, cows, goat, dog, hen, sheep etc.) recruited from three different zones (South, East, and New west zone) randomly out of six zones of Ahmedabad city, Gujarat, India. Data collected in vernacular language by using pretested questionnaire during the month of March to May 2017. Data entered into Excel and analyzed by using SPSS V.18. The burden was estimated in form of proportion of self-reported disease. The ethical permission was sought from the ethical review board of Indian Institute of Public Health Gandhinagar

\section{Results}

Total 170 animal handlers participated in this study and majority of them were females. Around $76 \%$ participants belonged to 26 to 60 years of age group with the mean age of $42 \pm 15$ years. There were $44 \%$ of respondents illiterate however out of total literate, $50 \%$ studied up to primary or more. Around one-third, respondents belonged to Below Poverty Line status.

The cumulative prevalence of self-reported $\mathrm{Z} / \mathrm{D} / \mathrm{S}$ was found $23 \%$ among respondents however amongst their family members was found $17 \%$. The point prevalence of self-reported $\mathrm{Z} / \mathrm{D} / \mathrm{S}$ during the study was found to be $17 \%$ and $18 \%$ amongst their family members. Self-reported Z/D/S includes vector born, animal bite and respiratory diseases.

Average experience and hours/day spent on handling animal was reported respectively $22 \pm 15 \mathrm{yrs}$ (median age of $20 \mathrm{yrs}$ ) and $5 \pm 2 \mathrm{hrs}$. It was observed that median value for types of breeds of animals was five ( $\mathrm{IQR}=3$ to 8 ) which ranged from 1 to 70 animals. Different breeds of animals reported by the livestock keepers, which included Buffalo 64\%, Cow 38\%, Goat 20\%, Dog 5\% and Sheep \& Bulls 4\%.

On inquiring about their perception on acquiring by virtue of engagement in animal handling can be a cause of the disease was reported by only one-third of participants. Knowledge about common zoonotic reported for rabies $(11 \%)$, respiratory disease $(10 \%)$ followed by vector born disease $(7 \%)$ and skin disease $(1.2 \%)$.
Average knowledge on the mode of transmission of $\mathrm{Z} / \mathrm{D} / \mathrm{S}$ was reported only $4.1 \%$.

The study also documented the commonly used methods for prevention of zoonotic disease, most common practice was found hand washing practice $(83 \%)$ followed by avoiding contact to animal placenta with naked hands $(68 \%)$.

\section{Conclusions}

The prevalence of self-reported $\mathrm{Z} / \mathrm{D} / \mathrm{S}$ was underestimated when compared to other studies within India. One of the common reasons could be poor awareness of $\mathrm{Z} / \mathrm{D} / \mathrm{S}$ amongst high-risk groups. Results suggest that it is important to initiate screening and improve the awareness of $\mathrm{Z} / \mathrm{D} / \mathrm{S}$ amongst animal handlers to improve the reporting of $\mathrm{Z} / \mathrm{D} / \mathrm{S}$.

Table 1: Disease Burden of last five years possibly linked to animal handling

\begin{tabular}{|c|c|c|}
\hline \multicolumn{2}{|c|}{ Variables } & $\mathrm{n}=170(\%)$ \\
\hline \multirow{2}{*}{ History of any disease among respondents } & Yes & $39(23)$ \\
\cline { 2 - 3 } & No & $131(77)$ \\
\hline \multirow{3}{*}{ Reported disease among respondents } & Chickengunya & $27(15.9)$ \\
\cline { 2 - 3 } & Animal bite/Rabies & $12(7.06)$ \\
\cline { 2 - 3 } & Tuberculosis & $1(0.6)$ \\
\hline \multirow{2}{*}{ History of disease any disease among family members } & Yes & $29(17.1)$ \\
\cline { 2 - 3 } & No & $150(88.2)$ \\
\hline \multirow{2}{*}{ Reported disease among family members } & Chickengunya & $22(13)$ \\
\cline { 2 - 3 } & Animal bite/Rabies & $4(2.35)$ \\
\cline { 2 - 3 } & Influenza HIN1 & $1(0.6)$ \\
\cline { 2 - 3 } & Tuberculosis & $4(2.35)$ \\
\hline \multirow{2}{*}{ Overall Household disease condition } & With disease & $55(32.35)$ \\
\cline { 2 - 3 } & Without disease & $115(67.65)$ \\
\hline
\end{tabular}

High risk practices of Animal Handlers (\%)

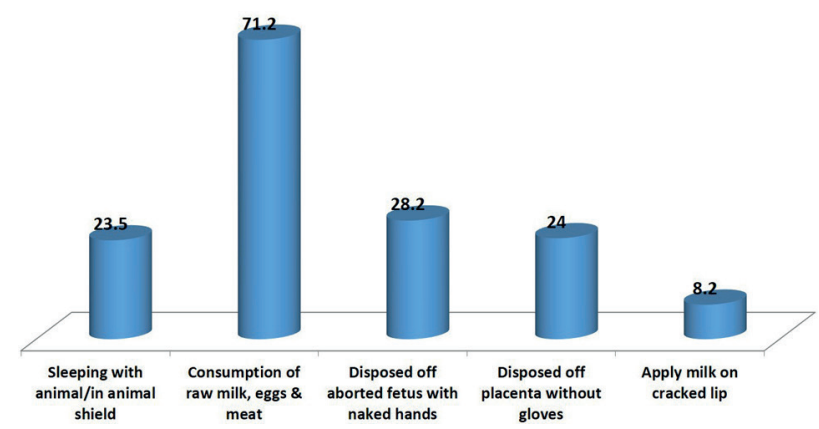

Knowledge \& Practices of Animal Handlers in Urban Ahmedabad

\section{Keywords}

Self Reported; Zoonotic Disease; Animal Handlers; Urban Area; Knowledge \& Practices

\section{Acknowledgments}

To all participants, Cattle Nuisance Control Department of Ahmedabad Municipal Corporation and Indian Institute of Public Health Gandhinagar for cooperation and support. 


\section{References}

[1] A Tripartite Concept Note. Sharing responsibilities and coordinating global activities to address health risks at the animal-humanecosystems interfaces, 2010.

[2] Dubal, Z.-B., Barbuddhe, S.B. and Singh, N.P. Important Zoonotic Diseases: Prevention and control. Technical Bulletin No. 39. ICAR Research Complex for Goa (Indian Council of Agricultural Research), Old Goa- 403 402, Goa, India, 2014.

\section{${ }^{\star}$ Krupali B. Patel}

E-mail:pkrups78@gmail.com 